\title{
Unveiling 'European' and 'International' Researcher Identities: A Case Study with Doctoral Students in the Humanities and Social Sciences
}

\author{
Betina Lopes ${ }^{1,2}, * \mathbb{( 1 )}$ and Mónica Lourenço ${ }^{2}$ (1) \\ 1 Department of Life Sciences, University of Coimbra, 3000-456 Coimbra, Portugal \\ 2 Research Centre for Didactics and Technology in the Education of Trainers (CIDTFF), University of Aveiro, \\ 3810-193 Aveiro, Portugal; monicalourenco@ua.pt \\ * Correspondence: blopes@ua.pt
}

Received: 29 June 2019; Accepted: 28 October 2019; Published: 29 October 2019

\begin{abstract}
The significance of 'identity' in doctoral studies is widely acknowledged. Nevertheless, despite much research on what is involved in the process of identification with/as a researcher, very little attention has been devoted to understanding the effects of the internationalization of higher education in promoting feelings of belonging to a researcher community that goes beyond the national space. This qualitative case study aims to understand whether and how doctoral students in the Humanities and Social Sciences develop a 'European' or 'international' researcher identity during their doctoral studies. To address this aim, in-depth semi-structured interviews were conducted with twelve home and international doctoral students from a Portuguese higher education institution. Results from thematic analysis suggest that although the dichotomy 'European'/'international' was not always clear in participants' minds, those students who undertook mobility experiences or took part in international research networks or supervisory teams were more likely to regard themselves as 'international' or 'European' researchers. The implications of these findings for doctoral programs in an era of internationalization are highlighted.
\end{abstract}

Keywords: researcher identity; doctoral studies; higher education; internationalization

\section{Introduction}

Within the growing literature on doctoral education, identity has emerged as a central topic of research. One of the reasons for this attention lies in the fact that one of the main goals of the $\mathrm{PhD}$ is the development of a researcher identity (Gardner 2008b; McAlpine et al. 2010; Byram et al. 2017). Indeed, becoming a professional researcher requires students to negotiate new identities and reconceptualize themselves both as people and professionals in addition to learning specific skills (Hall and Burns 2009).

The process of becoming a researcher has mainly been approached in extant literature as a 'socialization' process whereby researchers acquire the knowledge and skills, as well as the norms and ideologies necessary within a specific discipline, through contact with their peers (Parry 2007). Under this framework, studies suggest that undertaking and accomplishing a $\mathrm{PhD}$ entails, among others, the ability to conceive, design, and implement a substantial program of research with integrity; use and adapt established research methods; demonstrate critical analysis, evaluation and synthesis of new and complex ideas; frequently publish in high ranking academic journals (European Commission 2011; Hall and Burns 2009; Kehm 2004). Related research has focused on the transformative process that occurs during the doctoral learning journey. The idea of key-moments/phases in this journey comes up several times in the literature. According to Harrison (2009), doctoral learning is conceived as a process of identity construction and implies crossing 'thresholds of self-perception' that are experienced 
as 'stuck places' of anxiety and insecurity and resolved through a process of self-re-storying and repositioning, particularly in respect of knowledge and what it means to be a knower. In a similar vein, Kiley (2009) argues that doctoral candidates undergo changes in the way they understand their learning and themselves as learners. These are called 'rites of passage' and occur, for instance, when research candidates learn the language not merely of the subject area but of graduate research study and learn to 'act' as a graduate researcher, with the rigor and conceptual levels of thinking that is expected of them. Jazvac-Martek et al. (2011) emphasize the complexity of developing a researcher identity, which they regard as the result of experiences deriving not only from the doctoral program and from interactions with their peers (colleagues, supervisors, other researchers), but also from their past and on-going personal and professional lives. This perception is crystalized in the concept of 'identity trajectory' which "attends particularly to individual agency, nesting the academic within the personal and incorporating students' past as well as imagined future" (McAlpine 2012, p. 38).

Despite much research on what is involved in the process of identity construction as a doctoral researcher, very little attention has been devoted to understanding the effects of the internationalization of higher education (Knight 2004) in promoting feelings of belonging to a community that goes beyond the national space. In a similar manner, very few studies have investigated the characteristics of what constitutes 'European' or 'international' researcher identity. One of the few exceptions is Evans's (2010) proposal of a professional development model for European early career researchers. The framework identifies specific indicative characteristics of European researchers, which include self-perception as European, cultural awareness, and the ability to conduct research that addresses and/or has relevance to European specific issues, while incorporating considerations of relevant local and national contexts.

A recent study by Byram et al. (2017) also draws attention to the lack of empirical studies focused on researching the impact of globalization and internationalization processes on doctoral studies. In fact, since the initiation of the Bologna Process back in 1999 and the adoption of the Lisbon Strategy in 2000 (Diogo 2016; Kehm 2007), as well as of subsequent changes related with the creation of the European Higher Education Area and the European Research Area, the political higher education agenda has been explicitly and implicitly sustained on the intention of establishing a next generation of competitive scholars, who feel and act as 'European' (Diogo et al. 2019). But, like Byram et al. (2017) emphasize, the doubt remains: "Are researchers in Europe European researchers?". What factors are involved in this perception? Moreover, what role (if any) does this political agenda play in the construction of a researcher identity by non-European students conducting their studies in European higher education institutions?

This article aims to contribute to this discussion by investigating the process of the identity construction of seven home and five international doctoral students in the area of the Humanities and Social Sciences attending the University of Aveiro (UA), a public university in Portugal. The relevance of including international students in our sample is justified by the fact that in the last decade, as a consequence of internationalization processes, as well as national and institutional strategies focused on mobility schemes and attraction policies (Brandenburg and De Wit 2015; Lopes and Diogo 2019), the number of international students in Portuguese higher education has more than doubled (PORDATA 2019). This has particularly been the case of students coming from Portuguese-speaking countries, namely Brazil (South America), East Timor (Asia) and Angola, Guinea-Bissau, São Tomé and Príncipe and Mozambique (Africa) (Lopes and Diogo 2019). Considering this context, Portugal, a European country with the ability to attract students from almost every continent of the world, constitutes a privileged field case for exploring the complex phenomena of developing a researcher identity in a new globalized and ever-changing world.

It is worth highlighting that this study brings to light only one aspect of a broader study of the experience of doctoral research as seen by students, supervisors and other stakeholders involved in the doctoral process, such as examiners and directors of doctoral schools. In turn, this is part of a wider study - Strand 2 of the EUROMEC project (http://www.euromec.eu) - involving universities in Bulgaria, China, Luxembourg, Poland, Portugal and the UK (see Stoicheva and Byram 2019). 


\section{Doctoral Education at the University of Aveiro}

The University of Aveiro (UA) is a Portuguese public foundation operating under private law founded in 1973. Since its foundation, doctoral education has been a key mission of the institution. Initially, doctoral programs at the UA were structured according to an 'apprentice model' (Nerad 2012), with doctoral students receiving individual support to develop an independent research project and write the corresponding $\mathrm{PhD}$ thesis. In this early type of doctoral studies, mainly academic staff were enrolled. In 2006, when the Bologna Process was adopted in Portugal, most doctoral programs at the UA started a process of curriculum (re)design involving the attendance of course units and the implementation of a credit system (Diogo et al. 2019). Typically, a doctoral program is organized in three to four years: during the first year, doctoral students attend course units; in the subsequent years, they develop a research project, write a thesis and attend some course units aimed at the development of transversal competences, such as academic writing. The thesis public defense during a viva voice examination marks the final stage of the process.

One important landmark in doctoral education at the UA was the creation of the Doctoral School (EDUA) in 2011, whose mission is "to coordinate third cycle activities internally and externally, develop new innovative courses and admit candidates" (Assunção 2011). The EDUA also develops "specific measures to enhance the employability of holders of its doctoral degrees based on training needs and market requirements" (ibid.). In recent years, several initiatives have been pursued by the EDUA. Worthy of note is the Code of Practice that aims at enhancing the quality of the supervision process by defining the basis of the relationship between the supervisor and the doctoral candidate, highlighting the active role of both parties and their shared responsibilities during the doctoral process. This Code of Practice also includes the Duties of the Doctoral Candidate (e.g., to join a research community, to follow the ethical principles of scientific research, to actively publish results in international journals in their research area) and the Duties of the Supervisor, stating, amongst other aspects, that supervisors have to introduce doctoral candidates to the research culture by helping them develop critical thinking and become independent researchers.

Since 2008, the number of doctoral students at the UA has increased considerably. In 2017, the time of data collection, the number of newly admitted doctoral students totaled nearly 350 in a university of 5000 postgraduate students. Some of these students benefit from scholarships attributed under the aegis of national or international team projects or as a result of individual projects funded by government agencies, such as the Portuguese Foundation for Science and Technology (FCT) and the Portuguese development agency ("Instituto da Cooperação e da Língua"). Nevertheless, the majority fund themselves, combining attendance of doctoral programs with their professional careers.

In recent years, following an internationalization agenda focused on promoting incoming mobility (Lourenço et al.; Diogo et al. 2019) and in alignment with the national tendency, the number of international doctoral students at the UA has also increased, especially those coming from the Community of Portuguese-Speaking Countries (CPLP), which includes Angola, Brazil, Cape Verde, East Timor, Guinea Bissau, Mozambique and São Tomé and Príncipe. A striking example of this increment is the Doctoral Program in Education, which counts a percentage of nearly $50 \%$ international students.

\section{Methodology}

\subsection{Research Design}

As highlighted in the introduction, this study is part of a broader international comparative research, titled: “New European young researchers' identities. Exchanges and doctoral studies-an international study of processes and outcomes in the EU", which is a strand of the Jean Monnet Network on European Identity, Culture, Exchanges and Multilingualism (EUROMEC). The main aim of this strand was to understand how the internationalization of higher education is affecting the experience of the people (students, supervisors, examiners, program leaders) involved in doctoral education in Europe and beyond. Research focused on the Humanities and Social Sciences and on 
three overarching themes: supervision, languages and ('European'/'international') identity. These themes were separately analyzed by a team of researchers in six universities of the following countries: Bulgaria, China, Luxembourg, Poland, Portugal and the United Kingdom (see Figure 1). Afterwards, comparisons between institutions/countries were drawn.

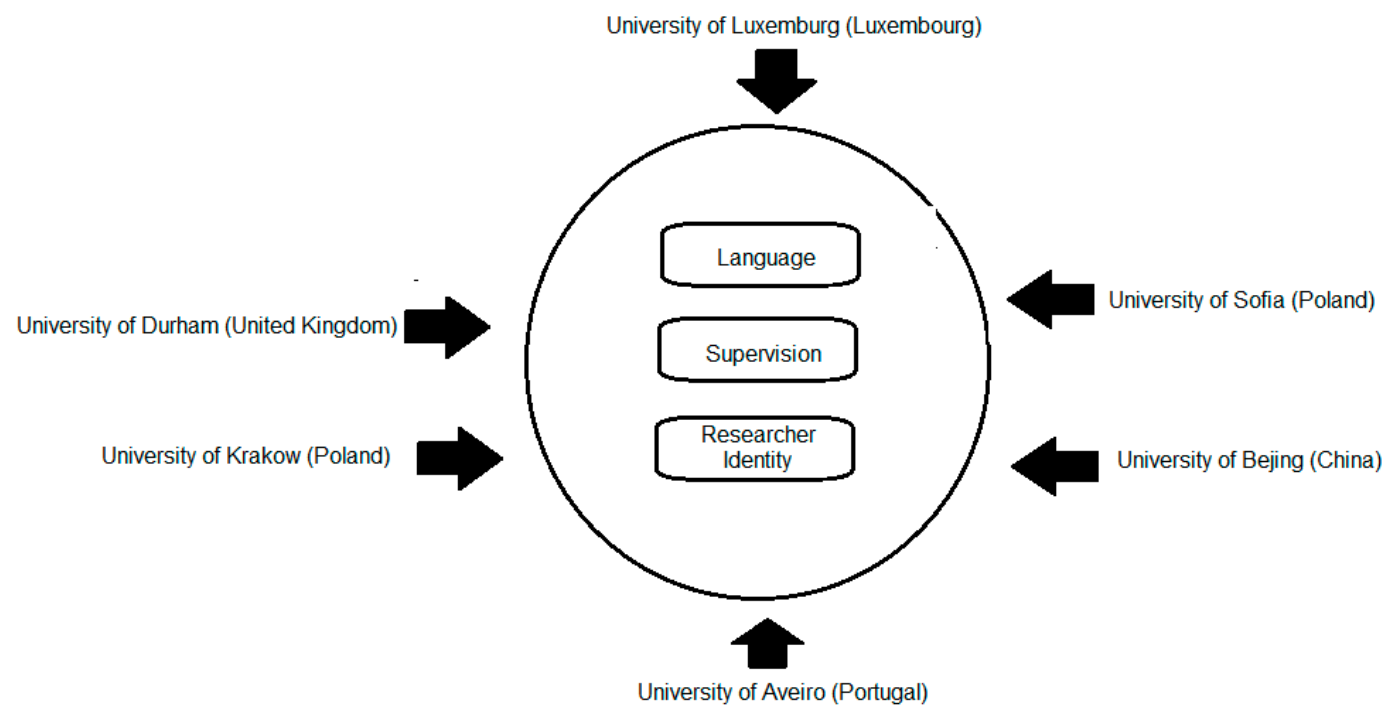

Figure 1. The European Identity, Culture, Exchanges and Multilingualism (EUROMEC) project—a comparative research of doctoral studies.

This paper reports on the results of a study conducted at the Portuguese university involved in EUROMEC - the University of Aveiro - and focused on the theme of identity. The study adopted a qualitative research approach of interpretive nature (Lopes et al. 2016), aiming not only at describing the phenomenon, i.e., the development of doctoral students' researcher identities in an era of internationalization (and 'Europeanisation') of higher education, but also at understanding the factors underlying this development. Therefore, the following research questions were defined: (1) What factors influence the development of an 'international' and/or 'European' researcher identity by doctoral students in the Humanities and Social Sciences attending a Portuguese university? (2) What kind of researcher profiles can be identified?

In order to address these questions, a case study was conducted in four Doctoral Programs in the Humanities and Social Sciences of the UA, the area with the highest number of PhD students (Diogo and Carvalho 2019): the Doctoral Program in Education, the Doctoral Program in Multimedia in Education, the Doctoral Program in Psychology, and the Doctoral Program in Gerontology and Geriatrics. The selection criterion relied on the fact that these programs are coordinated and/or co-coordinated by the Department of Education and Psychology, the largest department of the UA in this area. Participants were selected from these doctoral programs after initial contact with the course directors and/or their representatives, who got in touch with potential volunteers. At the end of this process, a total of twelve doctoral students, who had finished or were nearly finishing their doctoral studies, were chosen. In order to bring to light their insider experiences in relation to the theme of identity, semi-structured interviews were conducted. Details on the participants, as well as on the data collection and analysis instruments, are provided in the following sections.

\subsection{Participants}

Table 1 shows an overview of the twelve participants who are identified with the letter $\mathrm{S}$ followed by a number from 1 to 12. Students were distributed in the following way: seven were enrolled in the Doctoral Program in Education, three in Multimedia in Education, one in Psychology, and one in Gerontology and Geriatrics. Considering that student participation was voluntary, it was not possible 
to assure equal representation of all four doctoral programs. In terms of gender, eleven students were female, and one was male, which seems to reflect both an international and a national tendency in the Humanities and Social Sciences (Santiago et al. 2012). Students were aged between 28 and 57 years and were quite diverse in terms of their background and prior experiences. Five students were Portuguese nationals (S1 to S5), four came from Portuguese-speaking countries-Angola, Brazil, East Timor and Mozambique (S6, S7, S8 and S10)_and one came from the Ukraine (S9). Other participants included two Portuguese students who had undertaken mobility experiences in the United States (S11) and in the Czech Republic, Denmark, France and Norway (S12). Although most interviewees had studied in disciplinary areas related to their $\mathrm{PhD}$, two students had backgrounds in disparate areas, namely Accounting and Engineering. Six were full time students and five were working part time in other higher education institutions, e-learning companies or other organizations. The majority of the doctoral students had a scholarship from the Portuguese Foundation for Science and Technology (FCT). Other funding sources included fellowships from the Portuguese development agency ("Instituto da Cooperação e da Língua", I.P.), as well as scholarships from national governments, such as East Timor, which are assumed as relevant bilateral cooperation instruments between involved countries.

Table 1. Overview of the participants.

\begin{tabular}{|c|c|c|c|c|c|}
\hline Student & Gender & Type of Student & $\begin{array}{l}\text { Doctoral } \\
\text { Program }\end{array}$ & Background Area & Scholarship \\
\hline S1 & Female & Home student & Education & Math Education & $\begin{array}{c}\text { Yes } \\
(\mathrm{FCT})\end{array}$ \\
\hline $\mathrm{S} 2$ & Female & Home student & Psychology & Psychology & $\begin{array}{c}\text { Yes } \\
(\mathrm{FCT})\end{array}$ \\
\hline S3 & Female & Home student & $\begin{array}{l}\text { Gerontology } \\
\text { and Geriatrics }\end{array}$ & Social Work & No \\
\hline $\mathrm{S} 4$ & Female & Home student & Education & Social Work & $\begin{array}{c}\text { Yes } \\
(\mathrm{FCT})\end{array}$ \\
\hline S5 & Female & Home student & $\begin{array}{l}\text { Multimedia in } \\
\text { Education }\end{array}$ & $\begin{array}{l}\text { Information } \\
\text { Management }\end{array}$ & $\begin{array}{c}\text { Yes } \\
(\mathrm{FCT})\end{array}$ \\
\hline S6 & Male & $\begin{array}{l}\text { International student } \\
\text { (Mozambique) }\end{array}$ & Education & Chemistry Education & $\begin{array}{c}\text { Yes } \\
\text { (Instituto da Cooperação } \\
\text { e da Língua, I.P.) }\end{array}$ \\
\hline S7 & Female & $\begin{array}{l}\text { International student } \\
\text { (East Timor) }\end{array}$ & Education & Math Education & $\begin{array}{c}\text { Yes } \\
\text { (East Timorese } \\
\text { Government) }\end{array}$ \\
\hline S8 & Female & $\begin{array}{c}\text { International student } \\
\text { (Brazil) }\end{array}$ & Education & $\begin{array}{l}\text { Accounting, } \\
\text { Language and } \\
\text { Literature }\end{array}$ & $\begin{array}{l}\text { Yes } \\
(\mathrm{FCT})\end{array}$ \\
\hline S9 & Female & $\begin{array}{c}\text { International student } \\
\text { (Ukraine) }\end{array}$ & $\begin{array}{l}\text { Multimedia in } \\
\text { Education }\end{array}$ & $\begin{array}{l}\text { History and } \\
\text { Psychology }\end{array}$ & No \\
\hline $\mathrm{S} 10$ & Female & $\begin{array}{c}\text { International student } \\
\text { (Angola) }\end{array}$ & Education & Engineering & No \\
\hline S11 & Female & $\begin{array}{l}\text { Home student with } \\
\text { mobility experience }\end{array}$ & Education & $\begin{array}{l}\text { Language and } \\
\text { Literature }\end{array}$ & $\begin{array}{c}\text { Yes } \\
(\mathrm{FCT})\end{array}$ \\
\hline S12 & Female & $\begin{array}{l}\text { Home student with } \\
\text { mobility experience }\end{array}$ & Education & $\begin{array}{c}\text { Adult Education and } \\
\text { Educational } \\
\text { Psychology }\end{array}$ & $\begin{array}{l}\text { Yes } \\
(\mathrm{FCT})\end{array}$ \\
\hline
\end{tabular}

\subsection{Data Collection and Analysis}

Methodologically, all universities involved in Strand 2 of the EUROMEC project used the same data collection instruments and followed the same procedures. First participants were informed about the aims of this study and were assured that all data would be treated anonymously and confidentially. After obtaining institutional approval and written consent from each participant, individual semi-structured interviews were conducted by the research teams in each country. In the 
Portuguese case, each interview lasted between 45 and $90 \mathrm{~min}$ and was conducted in Portuguese, except for one interview (S11), which was conducted in English due to the participant's proficiency in this language. The interview schedule followed the guidelines defined by the Bulgarian, Luxembourgish and English teams of the project, and were based on two over-arching questions: What structures-formal such as regulations, and informal such as expectations of supervisors-exist, shape and evaluate the doctoral study process? and How is doctoral study experienced and perceived by participants? For the identity dimension they were asked, inter alia, to talk about questions of identity, with a view to unveil their trajectories in the process of becoming 'European' and/or 'international' researchers (see Appendix A).

All interviews were recorded, verbatim transcribed and submitted to a thematic analysis of interpretive nature (Braun and Clarke 2006), aimed at understanding doctoral students' perspectives and experiences, rather than merely identifying them. For this study, thematic analysis was conducted by two researchers of the Aveiro team, the authors of this paper, sustained mainly by a constructivist approach of grounded theory (Charmaz 2014), which combined description and interpretation. Analysis was both deductive and inductive and occurred as follows: first, the two researchers read through the data and identified words and phrases that could be linked to the research questions and to the terms already identified by the researchers in other institutions of the broader project. At this stage, unanticipated terms were also included. The terms were later refined in a recursive/iterative process that drew on the literature, and a more stable list of themes was created focusing on the factors that led to the development of ('international'/'European') researcher identities in our participants and later on their researcher profiles. The verification and consolidation of this process was achieved by a three-step peer debriefing process: first between the two researchers; then, between these two researchers and the other members of the Aveiro team, and finally, in a discussion with the members of the broader project. Each peer debriefing discussion involved the comparison of the selected evidences for the corresponding themes with the initial interview transcripts (rough data) and aimed at leading the process towards conceptual abstraction, enhancing trustworthiness, credibility and resonance of the findings (Tucker et al. 2016; Lopes et al. 2016). It is important to highlight that the researchers involved in this study are academics and supervisors themselves. That is, all the researchers involved in data

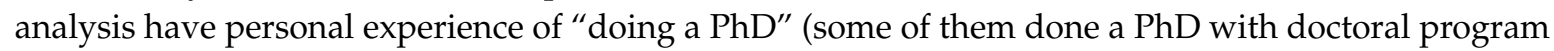
and others without). In alignment with the foundational assumptions of constructivist grounded theory, authors assume that interaction between interviewers and interviewees may affect data generation and analysis (Tucker et al. 2016; Lopes et al. 2016), in order to both minimize this fragility and elicit it to readers, authors care was taken to realize thick descriptions throughout the entire research process.

\section{Results and Discussion}

In this section, we bring to light students' discourses and perceptions in an attempt to identify key factors that may contribute to the development of 'European' and/or 'international' researcher identities. Moreover, we organize students' identities into profiles to demonstrate how the interplay of these factors may impact the sense of being (or not being) an ('international'/'European') researcher. Statements are illustrated by student quotations that provide fairly representative perspectives and perceptions of the larger group of participants. All quotations were translated from Portuguese into English for purposes of clarity, except in the case of S11, who was interviewed in English as reported above.

\subsection{Factors Associated with the Construction of 'European' or 'International' Researcher Identities}

Thematic analysis allowed us to identify three factors which were associated by the respondents with feelings of belonging to a broader European or international research community, namely: (i) networking, i.e., the opportunity to interact with a diverse range of people (other doctoral students, supervisors, experts in the area ... ) both at the institution and abroad; (ii) activities typically associated to the work of a researcher, such as publishing in international academic journals or reading literature in 
a foreign language and, finally, (iii) mobility and study abroad experiences, which often include the two previous factors. We explore each of these factors in more detail below.

\subsubsection{Networking}

The importance of networking within the doctorate to acquire the norms, knowledge, skills and behavior necessary to become a researcher in a specific domain is well documented (Colbeck 2008; Gardner 2008b; Jazvac-Martek et al. 2011; Weidman and Stein 2003). While conducting their studies, doctoral students create a web of local, national, and international relationships that consist of individual peers, more senior academics, student teams/groups in addition to their supervisors. Besides providing different kinds of support—personal, career or scholarly advice-these networks and the understandings gleaned from their experiences help students learn new roles and behaviors and enter a disciplinary culture. Therefore, they act as 'gateways' through which the students must pass (Gardner 2008b; Lopes et al. 2013), marking an important part of their overall socialization process.

Throughout the interviews, seven students alluded to how their colleagues were important for their learning, not just by helping them cope emotionally with the difficulties associated with the process of doing a $\mathrm{PhD}$, but also by contributing to their identification with a disciplinary domain. For example, S10, an international student from Angola with an engineering background, drew attention to how interaction with a diverse and multicultural group of people, during the first year of a curriculum-based doctorate, helped her fit in the broader community of educational research:

Because we are learning in groups, we have to deal with people of different backgrounds, of multiple disciplines ... even of different cultures ... it is a learning process ... and this broadens our perspective, our point of view, contributing to our personal development. [... ] This helped me to take off my engineering persona, my conceptual framework, which was embedded in engineering, and I started to think within the framework of education.

Still, she recognizes that integration was a difficult process, as a result of cultural difference. Although she did not label the situations she was involved in as 'discriminating', she often felt that she had to prove herself as a researcher (and an academic) to be accepted by her colleagues. A similar feeling was expressed by S6, an international student and university teacher from Mozambique. Acknowledging initial difficulties in integrating into the group of doctoral students in Education, he explained that he had to work harder than his peers in order to overcome the (low) expectations some of his teachers and colleagues had of him, and get himself into a position where he could just be acknowledged and respected for his personal contributions:

I think that I demand a lot of myself. But during the doctorate the demand I put on myself was bigger ... to try to match the expectations [... ]. But after a while I think that my colleagues and I came to the conclusion that we had to work on an equal footing ... And I think it is important to stress this: it's good to work in a multicultural context...

Identical experiences have also been reported in previous studies conducted with international doctoral students (Archer 2008; Gardner 2008a; Sherry et al. 2010), and with those coming from Portuguese-speaking African countries (Ambrósio et al. 2017; Lopes and Diogo 2019). These studies suggest that students who do not fit the traditional mold of graduate education in the West (i.e., anyone other than young, white males) struggle to fit into academia, experiencing negative interactions with others and a general feeling of 'differentness'. This tends to affect overall satisfaction and integration in the doctoral program, thus impairing the socialization process and the development of their selfand professional identities. Despite this, and considering the two previous quotes, curriculum-based programs sustained in a group work methodology seem to enhance networking opportunities and therefore play a crucial role in gradually helping students overcome hindrances and prejudice, thus acting as privileged places for broadening students' perspectives, promoting intercultural dialogue and therefore fostering their sense of belonging to a broader research community. 
Apart from their peers, doctoral students also highlighted the decisive role more experienced researchers and faculty members, namely their supervisors (S7, S2, S11) and other academics (S12), played in their becoming ('international') researcher identities. For example, S2 valued the learning process triggered by her supervisors, highlighting the advantages of working with an international supervision team (two Portuguese supervisors and a Swedish co-supervisor):

The possibility to work with so different people and to experience such different cultures, which seem distant but actually bring us closer, allows us to exchange knowledge and information ... so they took advantage of our knowledge and we took advantage of their knowledge. This was the most rewarding aspect ... having a project that was developed with people who are top experts in this area.

The contact with her Swedish supervisor led her to take a short-term internship in one of the world's leading medical institutions. This experience marked a turning point in her doctorate, allowing her to rethink the scope and relevance of her project: "that experience made me go deeper into my topic and determine the meaning that this line of research could have, not only locally but also internationally".

\subsubsection{Doing What Researchers Do}

S6's testimony offers a different take on networking, suggesting that the process of constructing an ('international' or 'European') researcher identity may go beyond personal networking, integrating what McAlpine (2012) terms 'intertextual networking'. For him, the intensive reading and writing activities he conducted during the doctorate helped him to contact with a network of key scholars and ideas pertinent to the thinking underlying the thesis, and to acquire the specific language that is shared within the research community (the 'tribe') of science education and sustainable development:

We ... as doctoral students ... read and write a lot. And during these reading process, we are actually learning, isn't it so? It is a process of learning a specific language, the thinking mode of that specific 'tribe'. When I say that I would like to bring Mozambique to the research community ... it is through the use of the specific language of that tribe ... and I think that it is happening ... I am learning to think and gather information in alignment with what is done in that specific community.

This reinforces the importance of experiencing activities that are 'automatically' linked with an international scope of research during the $\mathrm{PhD}$ (Byram et al. 2017). For instance, reading in another language to become aware of previous research developed in one's research field is considered by doctoral students to be mandatory. As S1 explains: "Nowadays, all PhDs have an international dimension, even if this is only related with the references used for the thesis".

Being able to explain the outcomes and value of their research, through publications in international journals and participation in academic conferences, is also considered to be a key characteristic of doctoral students' researcher profiles (European Commission 2011; Evans 2010; Lopes et al. 2013), as it will ultimately contribute to their recognition as 'researchers' by the research community itself (Hall and Burns 2009; Jazvac-Martek et al. 2011). In what comes to publishing the results of their research, all students were unanimous in stating that, despite being a lengthy and sometimes distressing process, this is an important part of the doctorate and of their affirmation as researchers. The following quotes from two national students (S1 and S5) stress the possibility (and necessity) to share their findings with the international research community:

When it comes to publishing our work, we are aware of the need to internationalize. Whoever thinks that it is enough to stay in Portugal and publish locally is wrong.

I think that publishing the results of our work is important ... What can we bring to the research community that is interesting? 
However, for international students, coming from African Portuguese-speaking countries and East Timor, publishing in their home countries was particularly relevant. As stressed by S8, an international student and academic from East Timor, "we rarely write articles or organize seminars and discussions there". Therefore, for these students, publications are seen a way to contribute to the advancement of research and teaching in their homeland.

I would like to publish in Mozambique. [ ... ] And I hope that some of my ideas, disseminated through this medium, can influence the development of education in Mozambique, namely the teaching of chemistry. (S6)

As regards attending conferences, only six out of twelve students mentioned that they had participated in events to disseminate their findings. Most of these events had a national scope, due to personal or financial constraints, as highlighted by S1:

I participated in several seminars and conferences in Portugal. Unfortunately, I was unable to participate in an international conference that is one of the best in my area of research, which took place in Chile. I submitted a proposal, was accepted, but I was not able to get funding. And that conference would result in the publication of an international article, it was not a book of proceedings ... It was a very good conference.

For those students who had the chance to participate in international conferences, the gains seemed to extend beyond publications and peer recognition though. Recalling a conference that she attended in the United States, S11 stressed how interaction with other PhD students helped her understand the need to present herself in a more 'professional' way and to be more confident speaking up her own ideas:

If we were going to a conference, they [my PhD colleagues] would present their business cards. They have business cards; here we don't. [ ... ] So, they are aware [... ] of how important it is to brand ourselves and how important it is to present yourself in a professional way. Here in Portugal it's different. [ .. . I don't want to offer stereotypes (we have to be careful with this), but we have to recognize that in Portugal we have this culture of being humble and sometimes ... I mean you have to be aware of your own rights and speak about your own ideas, about your work and ... to speak up your mind!

\subsubsection{Mobility Experiences}

For S11 and S12, who undertook mobility experiences in the United States and in Europe respectively, the benefits of moving across borders and cultures were immense, starting with a renewed awareness of the world around them, particularly the world of research. According to S12, the experiences of doing mobility in Denmark and France helped her to contact with different styles of academic work and to find her personal 'research niche':

The summer school [in Denmark] was fundamental for me to rethink the meaning of doing a $\mathrm{PhD}$. I remember that there was a teacher with whom I talked more often [ ... ] who told me the most interesting thing, which was ... all PhD theses that were supervised by him had a personal first chapter, where people described how their individual process of doing a PhD was. And this made me think ... I have been around this work for several years now ... it is personal, it has to be personal ... and this was when I decided to change the title of my thesis from plurilingual competences to plurilingual repertoires.

For S11, being a visiting scholar in the United States and contacting with other researchers and academics allowed her not only to become more aware of international standards and of different working traditions among the American academia and the Portuguese academia, but also to reconsider her own identity as a researcher. When asked if she considered herself an international researcher, she answered: 
I certainly made my best to be an international researcher. All institutions have their strengths and weaknesses and having the possibility to be a visiting scholar in another institution makes you more aware of what you have in your own country and how research is done in your country, and how research is handled on the other side of the ocean, in my case. So, I think that's quite important for all scholars.

Researcher mobility, for instance the one supported by the Erasmus program, has also been identified as an important factor by the Luxembourg case of the EUROMEC project. According to Byram et al. (2017), mobility plans and agreements between different European universities and in different countries may contribute to creating an identify of a doctoral researcher in Europe. Nevertheless, while this may be a desirable output for European citizens, it may be problematic for students coming from other countries, in particular developing countries, as it will be highlighted in the following section.

\subsection{Doctoral Students' Researcher Identities: Four Profiles}

After the identification of the key factors associated with the development of 'European' or 'international' researcher identities, the next analytical procedure that was taken was to single out, in students' discourses, similarities and differences related with their perceived ('European' and 'international') researcher identities. This process, which was also supported by literature review, allowed us to put together a taxonomy of four researcher profiles: (i) the knowledge worker; (ii) the budding ('international') researcher; (iii) the research ambassador, and (iv) the 'international' or 'European' researcher.

(i) Knowledge worker

Although the $\mathrm{PhD}$ is mainly considered a process of becoming a member of a research community, two students seemed to struggle with this idea. S3, a 50-year-old doctoral student, refused to identify herself as a researcher, envisioning her doctoral path as one that provided her with a 'broader view of the phenomena', of what research is and what it implies:

I don't consider myself a researcher, because I do not have ... I promised myself that I would not go back to studying ... I have been enrolled 34 times as a student [ ... ] So I do not feel like a researcher or want to think about it now. Of course, I'm saying that I do not want to, but if something comes up that interests me... But not in this sense of yet another title, because it requires a lot of personal involvement.

Throughout the interview, it became clear that probably her age in combination with her initial motivations for doing a $\mathrm{PhD}$, which were deeply tied with professional development in her working area, as well as the lack of mobility experiences or networking activities abroad, may have prevented her from developing a sense of self as a researcher (see Archer 2008).

While S3 easily excluded the hypothesis of feeling and working as a researcher, S5, a part-time e-consultant was more hesitant:

I do not know if I feel entirely like a researcher ... I have my doubts. That's because I have a foot in the business world, that's my experience. In the business world is where I feel more at ease. And I think my foot is still more on that side than on the research side...

This suggests that for these two students, whose main motivation in doing a PhD was grounded in professional development, the doctorate experience was not so much a foundation of an academic researcher career, but a means to become what Elsey (2007) describes as 'knowledge worker'—a person with advanced training in research and a knowledge expert in the profession. This is clearly in tune with the new reality of doing a doctorate. Indeed, professional doctorates, which are consolidating in the areas of Natural Sciences and Engineering (Cardoso et al. 2019), are now becoming a popular alternative to PhDs in the Humanities and Social Sciences, particularly for teachers who are interested in applying research to their professional areas or designing effective practice within their own field (Araújo e Sá et al. 2019; Breganha et al. 2019). 


\section{(ii) Budding ('international') researcher}

While S3 and S5 imagined their future outside academia, S1, S4, S8 and S9 expressed a desire to work professionally as researchers, whether in the medium or long run. S9 stated that she felt she was "becoming a researcher", since she had been collaborating in several research projects and acting as a co-supervisor in master's degrees. S1 was also very assertive assuming that her plan had always been to "become a researcher in the academy" and, therefore, obtaining a doctoral degree was a "requisite to enter into this career". Likewise, S4 assumed that she had always felt this desire in conducting research, since she had "always questioned her practice". From her point of view, it was this inquiry mode that propelled her to apply for a doctoral program. S8 also assumed that she would like to become a member of the research community of didactics and teacher education but felt that she needed to have a teaching experience before. Similar patterns were identified by Diogo and Carvalho (2019) who interviewed 22 international PhD students from the University of Aveiro, concluding that they still hold a traditional vision of a doctoral degree, mainly describing it as an 'entry ticket' for a professional career as a university teacher.

Despite regarding themselves as 'budding' researchers, waiting for the right 'opportunity structures' (McAlpine 2012) to apply their knowledge and their abilities, these four students seemed to be unaware of international research standards, stating "not to be aware of [them]" (S1), having "no idea" (S8) or "no knowledge about this" (S9) and being "not much into this subject" (S4). One of these researchers was even hesitant about describing her research as 'international', declaring: "I do not consider my work to be international ... because I conducted a very specific study with a very specific, very situated group of people..." (S8).

The fact that these four students had little mobility experiences, either through participating in international conferences or undertaking a period of study abroad, may also have contributed to a narrower view of the internationality associated to a researcher identity.

\section{(iii) Research ambassador}

S6, S7 and S10, three international students from Portuguese-speaking countries who had teaching duties in universities, stood out by explicitly integrating their researcher identities into their academic ones, regarding them as aspects of being a member of the scholarly profession (Colbeck 2008; McAlpine et al. 2010). Talking about their imagined futures, they expressed the desire to take back what they had learned to their home countries and continue pursuing research at their institutions in order to make a change, starting with their professional context:

At the professional level, it [the doctorate] will have an impact because I will have more knowledge about research, such as how to write an article. In East Timor, we rarely write articles or organize seminars and discussions. We still do not have a lot of research practice and I hope to start doing more of this with my colleagues there. We have new teachers and I have some plans to collaborate with them. I want to share my experience to incorporate them in this research dynamics.

This intrinsic desire to contribute to the development of their countries led us to profile these students as 'research ambassadors', i.e., people who have experienced research abroad and want to share their knowledge with others for their mutual benefit. Curiously, for these three students being an 'international' researcher means to be aware of Portuguese standards, in particular of the methodological principles researchers in Portugal apply, and to bring this way of doing research to their academic institutions:

[In order to be of an international standard, the research I conduct] has to be similar to what is done in Portugal but studying in a different context. [ . . ] It has to be similar in terms of the demands, the references, the research methodologies, all of that has to be similar, only the context, the study environment is different [... ] This gives me the sense of being an international researcher. 
The aspiration of these three international students in following 'Portuguese standards' and the emphasis on the idea that "all has to be similar" raises issues concerning the mainstreaming of Western knowledge and values (Nobes 2017; Santos 2003; Udoma et al. 2014). Therefore, this should be taken into account in doctoral programs in order to avoid that education for research contributes (even though unintendedly) to the phenomena of neo-colonialism (see, for instance, Stein et al. 2016; Lopes and Diogo 2019; Lopes; Udoma et al. 2014).

(iv) 'European' or 'international' researcher

Throughout the interviews, the conceptual difficult of distinguishing between 'European' and 'international' identity became evident (see also Byram et al. 2017). Striking, however, is that within the Portuguese case, a multicultural university with links to Europe but also to other continents, only three out of twelve students explicitly associated a 'European' or 'international' dimension to their professional identity as a researcher. Again, S11 and S12, who undertook mobility experiences abroad, stood out. Both students emphasized that they study international phenomena, support their studies with international references, publish in international journals, and have established an international network of scholars. This has, in their own perspective, allowed them to gain a sense of different research cultures and of the need to research not only in Portugal, but also in Europe and around the world.

S12, who is still developing her thesis, assumed that, in order to make her CV more competitive, she strategically seeks opportunities that are in tune with the requirements of a 'European doctorate', such as taking internships abroad:

I did not have the chance to have an Erasmus experience ... but I have always thought that it would be an asset for me, and for my work, to study abroad. So, I started searching and found 'European Doctorate' ... so I looked for the requirements ... and I discovered that there is a generic European recommendation ... and then there are some specificities in each university.

S11 also assumed that she pursued 'intercultural' experiences while doing the doctorate for both personal and professional reasons:

Yes, I went to the US [ ... ] because there was a strong master's program in International Education and my PhD research is situated in the field of International Education. So, I went for academic reasons. There was also a personal side to my stay in the United States, because, well ... as I was saying, I was an exchange student before, and once you are an exchange student, you are an exchange student for life. So, you feel that need to go to another institution to know other ways of working and to know other cultures.

These experiences abroad made her more conscious about the professional dimension of being a researcher and, curiously enough, allowed her to develop a sense of 'Europeanness', being this the only assumed case within the twelve students and the one more in tune with Evans (2010) model of European early career researchers. As she explains:

I would rather consider myself a European researcher with some awareness of how research is done in the United States. I would say that I am a European researcher, because everything I research is about Europe, and I have some awareness, to some extent, of how research is being done in the United States.

Finally, from the twelve interviewed students, S2 was the only one who expressed feeling like a full-fledged 'international' researcher. Having an international supervision team allowed her to establish her own international network of scholars with whom she still develops cutting-edge research. Furthermore, publishing in international journals and participating in international conferences contributed to her being recognized as an expert by her peers: 
Yes, I definitely feel like a researcher [ ... ] because now when there is a conference in my research domain, people easily identify me and say 'Oh, there is a person in Aveiro who is working on this'.

When asked at the end of the interview how she imagined her future, she promptly answered that it would be the continuation of what she is presently doing-lecturing in a higher education institution, researching in an area that is recognized internationally, and including some of her students in her international network of collaborators, just like her supervisors did with her.

\section{Concluding Remarks}

This study aimed to understand how home and international doctoral students in the Humanities and Social Sciences develop their researcher identities, particularly considering the sense of belonging to a research community that goes beyond the national space. For this matter, in-depth semi-structured interviews were conducted with doctoral students from a Portuguese higher education institution. Results from thematic analysis suggest that although the dichotomy 'European'/'international' was not always clear in participants' minds, those students who undertook mobility experiences or took part in international research networks or supervisory teams were more likely to regard themselves as 'international' or 'European' researchers. Indeed, these students found opportunities to learn from different research traditions, develop (inter)cultural awareness, and position their own research within a supranational framework. Doctoral students' profiles also show that 'becoming' a researcher is not smooth, straightforward, linear or automatic; it is not dependent on the doctorate experience per se, but on the synergistic or antagonistic interplay between several factors. If the activities and interactions carried out throughout the doctorate seem to be important to acquire new understandings about students' specific research themes ('disciplinary expertise') and about the core activities that they have to undertake as professional ('international' or 'European') researchers, cross national mobility experiences seem to contribute, in a more decisive manner, to extended perceptions of how to do research that is internationally relevant and how to behave as an ('international') researcher.

These findings have clear implications both for the practice and policy of doctoral education. Indeed, they show that it is not enough to state in policy documents, either at national or supranational level, the intention to educate researchers that feel and act as 'European' or 'international'. Concreate (financial and professional development) measures to support institutions and those responsible for the education of these researchers are clearly mandatory. Furthermore, results suggest that it is useful to (re)consider the international dimension of doctoral programs across European higher education institutions. These should not be reduced to recruiting doctoral candidates from other countries, often regarded as the only indicator for the internationalization of higher education. Instead, doctoral programs must provide more opportunities for all doctoral students (both 'home' and 'international') to integrate international research teams and networks, to participate in international events, and undertake short-term mobility periods. This might be one step forward towards educating researchers that are aware of their role in an increasingly globalized and interconnected world in which the social impact of research is paramount.

Author Contributions: The two authors contributed equally to the manuscript and their names are listed alphabetically.

Funding: This article is based on and produced as a part of an EU-funded Jean Monnet network project 'EUROMEC' led by Professor Maria Stoicheva, Sofia University, Bulgaria. Strand 2 of the project is entitled: 'New European young researchers' identities. Exchanges and doctoral studies-an international study of processes and outcomes in the EU' with partners from St Kliment Ohridski University, Sofia, Bulgaria; Jagiellonian University, Krakow, Poland; University of Luxembourg; University of Durham, UK; University of Aveiro, Portugal; and Beijing Language and Culture University, China.

Conflicts of Interest: The authors declare no conflict of interest. The funders had no role in the design of the study; in the collection, analyses, or interpretation of data; in the writing of the manuscript, or in the decision to publish the results. 


\section{Appendix A Interview Schedule-Doctoral Students}

\section{Appendix A.1 International/European Identity}

We are interested in the idea of 'international standards' in doctoral work and whether those doing a PhD feel in some way 'international' or 'European'. Perhaps first we can just talk about PhD studies in other countries. Do you know about PhD studies in other countries and, if so, can you tell us a little of what you know?

Possible prompts

- $\quad$ Does the phrase 'international standards in doctoral work' (or perhaps 'European standards') have meaning for you and, if so, can you explain how you understand it?

- Do you know/how do you know if the work you are doing is of an 'international standard'?

- $\quad$ [if international or mobile student] Some people say that studying in another country creates a sense of being an 'international' researcher or a 'European' researcher. Does this describe in any way how you feel?

\section{Appendix A.2 Identity as Researcher}

We are also interested to know more about how doing a $\mathrm{PhD}$ is a process of becoming a member of a discipline, or as some people say of becoming a member of a disciplinary 'tribe' or 'club'. In particular, we are interested in the language/discourse which is learnt as part of this process. Is this how you see the process of doing a $\mathrm{PhD} /$ for example does it make you feel that you are becoming or are now a 'real' researcher, a 'real' member of your discipline?

Again, we are interested in the role of language in this. Some people say that becoming a member of a discipline is a matter of learning the language e.g., to 'talk like a historian or a psychologist' or to 'use the language of history or psychology'. Is this your experience?

\section{References}

Ambrósio, Susana, João Filipe Marques, Lucília Santos, and Catarina Doutor. 2017. Higher education institutions and international students' hindrances: A case of students from the African Portuguese-speaking countries at two European Portuguese universities. Journal of International Students 7: 367-94. [CrossRef]

Araújo e Sá, Helena, Nilza Costa, Cecília Guerra, Betina Lopes, Mónica Lourenço, and Susana Pinto. 2019. Case studies-University of Aveiro, Portugal. In The Doctorate as Experience in Europe and Beyond. Edited by Michael Byram and Maria Stoicheva. Abingdon: Routledge, in press.

Archer, Louise. 2008. Younger academics' constructions of 'authenticity', 'success' and professional identity. Studies in Higher Education 33: 385-403. [CrossRef]

Assunção, Doutor Manuel António Cotão de. 2011. No. 6403/2011, approves the Regulation of the Doctoral School of the University of Aveiro, 14 April.

Brandenburg, Uwe, and Hans De Wit. 2015. The end of internationalization. International Higher Education 6: 15-17. [CrossRef]

Braun, Virginia, and Victoria Clarke. 2006. Using thematic analysis in Psychology. Qualitative Research in Psychology 3: 77-101. [CrossRef]

Breganha, Graça M., Nilza Costa, and Betina Lopes. 2019. Avaliação sumativa das aprendizagens em Física no $1^{\circ}$ ciclo do ensino secundário através de provas escritas-o caso de uma escola pública do município de Lubango (Angola) [Summative assessment of learning in Physics in the 1st cycle of secondary education through written tests-The case of a public school in the municipality of Lubango (Angola)]. Indagatio Didactica 11: 209-31.

Byram, Michael, Adelheid Hu, and Mizanur Rahman. 2017. Are researchers in Europe European researchers? A study of doctoral researchers at the University of Luxembourg. Studies in Higher Education 44: 486-98. [CrossRef]

Cardoso, Sónia, Orlanda Tavares, and Cristina Sin. 2019. Can you judge a book by its cover? Industrial doctorates in Portugal. Higher Education, Skills and Work-Based Learning. [CrossRef] 
Charmaz, Kathy. 2014. Constructing Grounded Theory, 2nd ed. Thousand Oaks: Sage.

Colbeck, Carol L. 2008. Professional identity development theory and doctoral education. New Directions for Teaching and Learning 113: 9-16. [CrossRef]

Diogo, Sara. 2016. Changes in Finnish and Portuguese Higher Education Governance: Comparing National and Institutional Responses to the Bologna Process and New Public Management. Ph.D. dissertation, University of Aveiro, Aveiro, Portugal.

Diogo, Sara, and Teresa Carvalho. 2019. What am I doing here? Reasons for international students to enroll in a PhD in Portugal. Paper presented at the 13th International Technology, Education and Development Conference, Valencia, Spain, March 11-13; pp. 4490-502.

Diogo, Sara, Anabela Queirós, and Teresa Carvalho. 2019. 20 years of the Bologna Declaration-A literature review on the globalization of Higher Education. Paper presented at the 11th International Conference on Education and New Learning Technologies, Palma, Spain, July 1-3; pp. 5196-209.

Elsey, Barry. 2007. After the doctorate? Personal and professional outcomes of the doctoral learning journey. Australian Journal of Adult Learning 47: 379-405.

European Commission. 2011. Towards a European Framework for Research Careers. Brussels: European Commission, Directorate General for Research and Innovation.

Evans, Linda. 2010. Developing the European researcher: 'Extended' professionality within the Bologna process. Professional Development in Education 36: 663-77. [CrossRef]

Gardner, Susan K. 2008a. Fitting the mold of graduate school: A qualitative study of socialization in doctoral education. Innovative Higher Education 33: 125-38. [CrossRef]

Gardner, Susan K. 2008b. 'What's too much and what's too little?' The process of becoming an independent researcher in doctoral education. Journal of Higher Education 79: 326-50. [CrossRef]

Hall, Leigh A., and Leslie D. Burns. 2009. Identity development and mentoring in doctoral education. Harvard Educational Review 79: 49-70. [CrossRef]

Harrison, Janet E. 2009. Developing a Doctoral Identity-A Narrative Study in an Autoethnographic Frame. Ph.D. dissertation, University of KwaZulu, Natal, South Africa.

Jazvac-Martek, Marian, Shuhua Chen, and Lynn McAlpine. 2011. Tracking the doctoral student experience over time: Cultivating agency in diverse spaces. In Doctoral Education: Research-Based Strategies for Doctoral Students, Supervisors and Administrators. Edited by Lynn McAlpine and Cheryl Amundsen. London: Springer, pp. 17-36.

Kehm, Barbara M. 2004. Developing doctoral degrees and qualifications in Europe: Good practice and issues of concern-A comparative analysis. In Doctoral Studies and Qualifications in Europe and the United States: Status and Prospects. Edited by Jan Sadlak. Bucharest: UNESCO/CEPES, pp. 279-98.

Kehm, Barbara M. 2007. Quo vadis Doctoral Education? New European approaches in the context of global changes. European Journal of Education 42: 307-19. [CrossRef]

Kiley, Margaret. 2009. Identifying threshold concepts and proposing strategies to support doctoral candidates. Innovations in Education and Teaching International 46: 293-304. [CrossRef]

Knight, Jane. 2004. Internationalization remodeled: Definition, approaches, and rationales. Journal of Studies in International Education 8: 5-13. [CrossRef]

Lopes, Betina, and Sara Diogo. 2019. Institutional challenges in monitoring and evaluating cooperation protocols between higher education institutions in Portuguese speaking countries. Paper presented at the 13th International Technology, Education and Development Conference, Valencia, Spain, March 11-13; pp. 1563-66.

Lopes, Betina, Maria João Macário, Mariana Pinto, Maria Helena Ançã, and Maria João Loureiro. 2013. Learning transitions of three doctoral students in a Portuguese higher education institution facilitated by the use of ICT. International Journal of Continuing Engineering Education and Lifelong Learning 23: 179-93. [CrossRef]

Lopes, Betina, Helena Pedrosa-de-Jesus, and Mike Watts. 2016. The old questions are the best: striving against invalidity in qualitative research. In Theory and Method in Higher Education Research. Edited by Jerome Huisman and Malcolm Tight. Bingley: Emerald Group Publishing, pp. 1-22.

Lopes, Betina. Forthcoming. As universidades públicas portuguesas e a capacitação na área da Educação em Ciências no âmbito da Cooperação Internacional para o Desenvolvimento: do mapeamento à sua problematização [Portuguese public universities and training in the field of science education in the context of international cooperation for development: from mapping to problematization]. Revista Lusófona de Educação. 
Lourenço, Mónica, Ana Isabel Andrade, and Michael Byram. Forthcoming. Representations of internationalisation at a Portuguese Higher Education Institution: From institutional discourse to stakeholders' voices. Revista Lusófona de Educação.

McAlpine, Lynn. 2012. Identity-trajectories: Doctoral journeys from past to present to future. Australian Universities' Review 54: 38-46.

McAlpine, Lynn, Marian Jazvac-Martek, and Nick Hopwood. 2010. Doctoral student experience in Education: Activities and difficulties influencing identity development. International Journal for Researcher Development 1: 97-110. [CrossRef]

Nerad, Maresi. 2012. Conceptual approaches to doctoral education: A community of practice. Alternation 19: 57-72.

Nobes, A. 2017. Challenges Faced by Early Career Researchers in Low and Middle Income Countries-How can We Support Them? Available online: http://gheg-journal.co.uk/2017/01/challenges-faced-early-careerresearchers-lmics-support/ (accessed on 16 August 2019).

Parry, Sharon. 2007. Disciplines and Doctorates. Dordrecht: Springer.

PORDATA. 2019. Foreign Students Enrolled in Higher Education (ISCED 5-8) (2000-2012). Available online: https://www.pordata.pt/en/Europe/Foreign+students+enrolled+in+higher+education+(ISCED+ $5+8)+(2000+2012)-1313$ (accessed on 10 August 2019).

Santiago, Rui, Teresa Carvalho, and Agnete Vabø. 2012. Personal characteristics, career trajectories and sense of identity among male and female academics in Norway and Portugal. In Effects of Higher Education Reforms: Change Dynamics. Edited by Martina Vukasović, Peter Maassen, Monika Nerland, Bjørn Stensaker, Rómulo Pinheiro and Agnete Vabø. Rotterdam: Sense Publishers, pp. 279-303.

Santos, Boaventura Sousa. 2003. Reconhecer Para Libertar: os Caminhos do Cosmopolitanismo Multicultural. Rio de Janeiro: Civilização Brasileira.

Sherry, Mark, Peter Thomas, and Wing Hong Chui. 2010. International students: A vulnerable student population. Higher Education 60: 33-46. [CrossRef]

Stein, Sharon, Vanessa de Oliveira Andreotti, and Rene Suša. 2016. 'Beyond 2015', within the modern/colonial global imaginary? Global development and higher education. Critical Studies in Education. [CrossRef]

Stoicheva, Maria, and Michael Byram. 2019. The Doctorate as Experience in Europe and Beyond. Abingdon: Routledge, in press.

Tucker, Virginia M., Christine Bruce, and Sylvia L. Edwards. 2016. Using grounded theory to discover threshold concepts in transformative learning experiences. In Theory and Method in Higher Education. Edited by Jeroen Huisman and Malcolm Tight. Bingley: Emerald, vol. 2, pp. $23-46$.

Udoma, Ogenna, Sarah Glavey, Sarah O’Reilly Doyle Martina, Hennessy Frank Barry, Mike Jones, and Malcolm MacLachlan. 2014. Research Capacity Building in Africa: perceived strengths, weaknesses, opportunities and threats impacting on the doctoral training for development programme in Africa. In Enacting Globalization. Edited by Brennan Louis. London: Palgrave MacMillan, pp. 42-53.

Weidman, John C., and Elizabeth L. Stein. 2003. Socialization of doctoral students to academic norms. Research in Higher Education 44: 641-56. [CrossRef]

(C) 2019 by the authors. Licensee MDPI, Basel, Switzerland. This article is an open access article distributed under the terms and conditions of the Creative Commons Attribution (CC BY) license (http://creativecommons.org/licenses/by/4.0/). 